Please send trade news information and

illustrations to Arveen Bajaj at the $B D J$, Nature

Publishing Group, The Macmillan Building,

4-6 Crinan Street, London N1 9XW.

Trade news is provided as a service to readers

using text and images from the manufacturer,

supplier or distributor and does not imply

endorsement by the BDJ. Normal and prudent

research should be exercised before purchase or

use of any product mentioned.

\section{Serious suction}

The Metasys Excom is a combination of a suction unit, an air-water separation unit and an amalgam separator. The Excom ZA5 System will provide all the suction you need for up to five chairs.

Even when used for several hours at a time the units guarantee a constant suction rate and can be sited almost anywhere for complete versatility. Fitted with condensate separators, the Metasys Vac dry suction systems offer additional security against condensation and optional air filters to reduce germs. The air by-pass valve for the adjacent air flow offers further protection to prevent overheating of the electrical motor as

\section{Remineralising toothpaste launched}

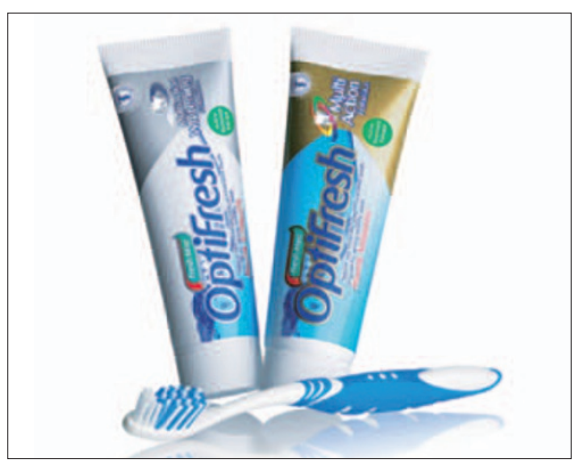

well as maintaining constant negative pressure. They are supplied complete with control box and condensate filters. Reader response number 50

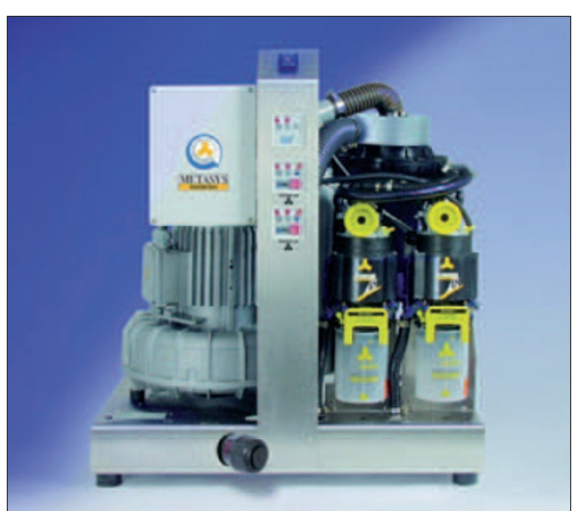

Swedish cosmetics company Oriflame has launched its first toothpaste, Optifresh, to the UK oral care market. Combining nature with science, it contains the Optifresh Advanced Remineralising System, a combination of sea algae (rich in zinc, iron, calcium, and phosphor) that helps to remineralise tooth enamel, and fluoride which protects teeth from acids known to cause cavities and tooth decay.

The range comprises of Optifresh multi-action with a sweet mint flavour and Optifresh multi-action whitening toothpaste with cool water mint flavour. Reader response number 52

\section{New fun kids range for all stages}

GlaxoSmithKline Consumer Healthcare (GSK) has launched a new range of children's toothbrushes and toothpastes under the Aquafresh brand name. Aquafresh Milk Teeth, Little Teeth and Big Teeth reflect the stages in a child's oral health development with stepped fluoride levels and flavours and specially designed motivational toothbrushes.

Aquafresh Milk Teeth toothpaste and toothbrush is formulated for baby teeth and gums while the Little Teeth toothbrush has a chunky easy grip handle and includes a travel cap with motivating character designs. Big Teeth toothpaste is suitable for age $6+$ years and the range includes a grown up toothbrush and antibacterial mouthwash with a mild mint flavour.

Reader response number 51

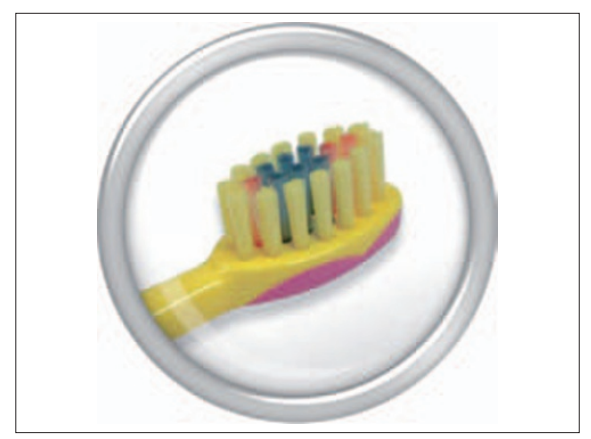

\section{Reducing cross contamination}

The Hygitech brand from Dental Sky has added three more products to its range.

The Hygitech Shoe Cover Dispenser saves you the trouble of bending down to don shoe covers as well as helping to prevent cross contamination from inadvertently touching dirty footwear.

Simply step on to the centre of the shoe cover dispenser and the shoe cover will be released immediately. The Hygitech Spray is a fully automatic, touchfree dispenser for alcohol hand rubs that assists in the prevention of cross contamination. Without the need to handle anything, the unit automatically detects your hand and dispenses the hydro alcoholic disinfection solution. There is a convenient clear window to allow you to check the level of solution without having to open the front cover.

Finally the Hygitech Perfume Dispenser can be used to deodorise your surgery, waiting room, rest rooms or wherever there is a need. With a smart remote control that works up to a distance of 25 metres you can programme the unit to dispense one of the three scents according to your needs. Choose from lemon, sunrise or elegant scents. Reader response number 53

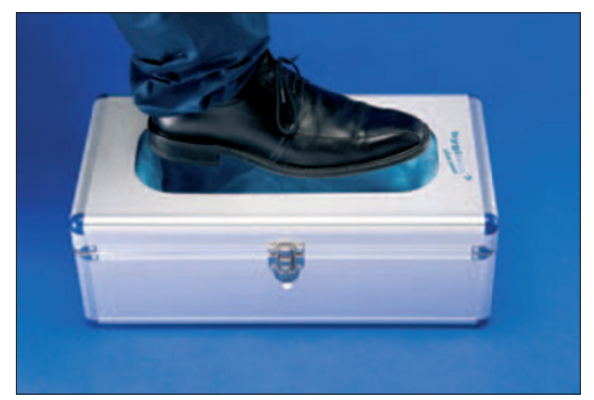




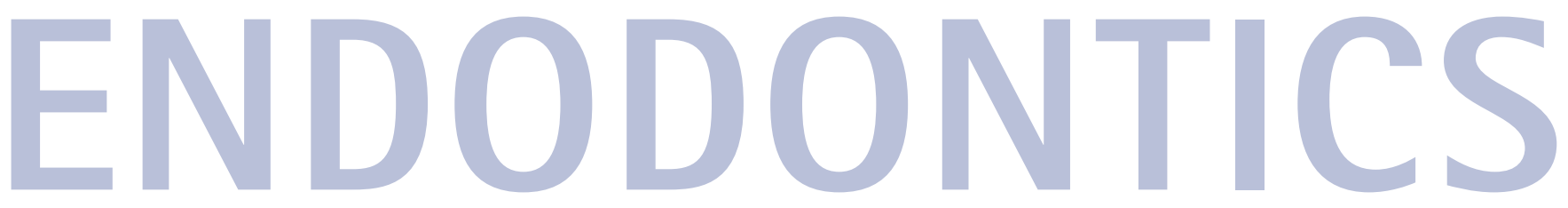

\section{Precision intruments with ergonomic handling}

Red Apple Dental Supplies offers an extensive range of quality FKG Endodontic instruments. Manufactured with Swiss precision from surgical grade stainless steel, the range includes innovative products such as the Sensipast and Ergoflex files and the Race reamer.

Also available is FKG's range of endodontic accessories such as stop dispensers, stop cartridges, rubber stops and endo boxes. The Sensipast paste filler is efficient and the spirals automatically disengage when any abnormal pressure is exerted on them to avoid periapical penetration.
Ergoflex $\mathrm{H}$ and $\mathrm{K}$ files have a progressive cutting edge and an ergonomic handle for restricting rotation. This reduces the possibility of introducing to a greater depth than desired to avoid apex perforation. The stem has a constant diameter for

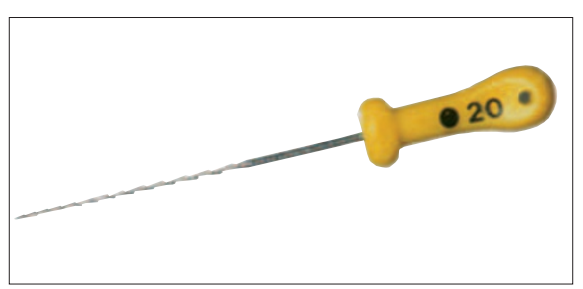

maximum flexibility and has a rounded tip. As part of FKG's patented endodontic system, Race reamers have alternate cutting edges to eliminate screwing and blocking.

The sharp edges give optimum cutting efficiency and the combination of triangular section and the alternating edges ensures efficient evacuation of chips and debris. The safety tip ensures sure guidance and centering of the instrument and the flexibility of the NiTi respects the trajectory of the original canal. The race reamers are available in 2, 4, 6 and $10 \%$ tapers.

Reader response number 54 


\section{Pre-sterilised packs}

Quality Endodontic Distributors Ltd have introduced pre-sterilised $\mathrm{K}$ and $\mathrm{H}$ Type SteriFiles in individual blister packs. Sterilised by gamma irradiation, which enables their use straight from the pack, SteriFiles can reduce the risk of stick injuries, cut costs and save time.

SteriFiles K Type files are manufactured from high-grade stainless steel with a triangular cross section, which maximises both flexibility and strength. Featuring an enhanced non-cutting tip, they are suitable for preparing curved and narrow canals and are available in packs of six, in $21 \mathrm{~mm}$ and $25 \mathrm{~mm}$ lengths, ISO 06 to 80 and assorted.

\section{Improved diagnostics}

Endodontic procedures can become more comfortable with Senseus stainless steel hand files from Dentsply. Its new silicone handles are less harsh on your fingers while the silicone also gives a better grip, improving tactile feedback and the torque and force transmission. Another new feature is their X-ray calibration rings, giving rise to improved diagnos-

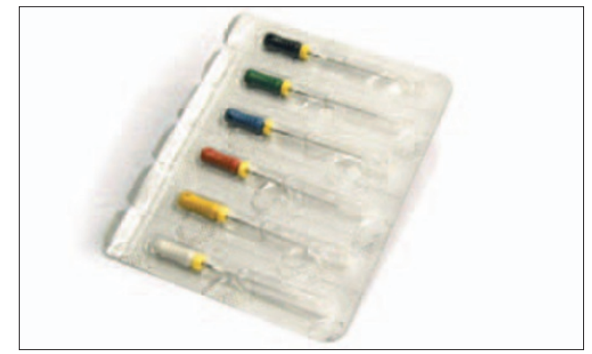

SteriFiles $\mathrm{H}$ Type files are aggressive Hedstroem hand files, which cut in an outward pull motion. Their unique core geometry gives them greater strength and less chance of breakage. They are available in packs of six, in $21 \mathrm{~mm}$ and $25 \mathrm{~mm}$ lengths, ISO 08 to 40 and assorted.

Reader response number 55

\section{Accuracy and control}

NSK's iPex digital apex locator allows accuracy and control during endodontic treatment. It enables you to accurately measure the length of the root canal in all conditions.

By automatically selecting the best possible frequency to suit the prevailing clinical condition, iPex makes a significant contribution to safer interventions and patient comfort.

Predictability is assured with iPex's large LCD display and audio signal. Offering you clear visibility and simple operation it provides accurate information for safer, more precise root canals. Reader response number 57 tics, precision and visibility. The range includes Flexofiles, Hedstroems, FlexoReamers and the ProFinder file.

The ProFinder is a dual-tapered file used to establish a glide path quickly and easily. This file is therefore ideal for use with the ProTaper Universal rotary file system as the tip size of the largest ProFinder is the same as the shaper 1 in the ProTaper system (017).

Reader response number 56

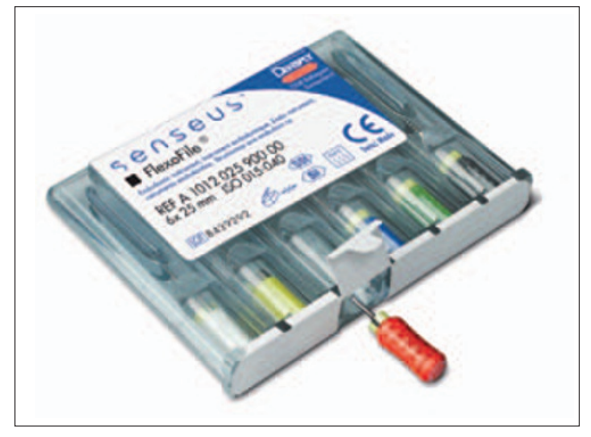

